\title{
Tramadol Hydrochloride
}

National Cancer Institute

\section{Source}

National Cancer Institute. Tramadol Hydrochloride. NCI Thesaurus. Code C29508.

A synthetic codeine analogue, Tramadol Hydrochloride has central analgesic properties with effects similar to opioids, such as morphine and codeine, acting on specific opioid receptors. The hydrochloride salt of Tramadol and used as a narcotic analgesic for severe pain, it can be addictive and weakly inhibits norepinephrine and serotonin reuptake. $(\mathrm{NCl04})$ 